DOI: $10.20472 /$ IAC.2018.041.005

\author{
ANAS ALQUDAH \\ Abu Dhabi University, United Arab Emirates
}

.AHMED YAMEN

1. Ain Shams University . 2. The American University of the Middle East, Kuwait

AHMED BANI-MUSTAFA

The American University of the Middle East, Kuwait

\title{
IMPACT OF CULTURE ON TERRORIST FINANCING: THE ROLE OF PUBLIC GOVERNANCE
}

\begin{abstract}
:
In this study, we investigate the role of public governance in mediating the effect of culture on terrorist financing (TF). Although culture has a significant impact on terrorism financing, the government can use the control of corruption (COC)and the rule of law (ROL) as useful tools in mitigating or eliminating this impact. We examine whether the $\mathrm{COC}$ and ROL can mediate the effect of culture on terrorist financing across 78 countries. We use Basel Anti-Money Laundering (AML) Index as a proxy for the risk terrorist financing, Hofstede's cultural dimensions for culture measuring and $\mathrm{COC}$ and ROL as indicators for public governance. The results reveal a complete mediation for $\mathrm{COC}$ and ROL to the impact of culture on terrorism financing.
\end{abstract}

\section{Keywords:}

Public Governance, Terrorist Financing, Currption

JEL Classification: A10, A13 